\title{
SHEAR BOND STRENGTH OF TWO PORCELAIN REPAIRING SYS- TEMS USING DIFFERENT SURFACE PREPARATION TECHNIQUES
}

\author{
Yasser Elkady*, Mohammed H Abdel-Aziz ${ }^{* *}$, Ahmed El Kouedi*** and T.A Hamza****
}

\begin{abstract}
Statement of the problem: Fracture or chipping of veneering porcelain in PFM restorations is considered to be a very common failure in clinical practice. Many clinicians are using different intra- oral surface preparation techniques and repairing systems. However, the success rate is still of concern to be verified as an acceptable treatment modality. Materials and methods: A total of 40 circular porcelain fused to metal specimens with $1 \mathrm{~cm}$ in diameter and $4 \mathrm{~mm}$ thickness were fabricated using feldspathic porcelain (VITA VMK Master, VITA, Germany) and nickel chromium base metal alloy (Wiron Light, BEGO, Germany). All 40 samples were subjected to 3000 cycles of thermo-cycling before the repair was performed. The specimens were divided into two equal groups of 20 samples each according to the repairing system used. (V; one step self-adhesive flowable composite resin, Vertise Flow, Kerr) and (F; two steps, Embrace First Coat, Pulpdent) followed by the application of self-adhesive composite resin (Vertise Flow). Each group of the two main groups was divided into two equal subgroups of 10 samples each according to the surface treatment applied before repair. (D; diamond stone surface roughening) and (H; hydrofluoric acid etching). Half of the specimens were subjected to accelerated photo-thermal aging before testing the shear bond strength. Shear bond strength was determined using NEXYGEN from Lloyd Instruments at a crosshead speed of $0.5 \mathrm{~mm} / \mathrm{min}$. Statistical analysis was carried out using Kolmogorov-Smirnov and Shapiro-Wilk tests. Results: No statistically significant differences were found between the two repairing systems or between the two surface treatments either before or after accelerated photo-thermal aging. The only significant difference was recorded between the two subdivisions where the two steps system was used on etched surfaces before and after photo-thermal aging. Conclusion: The one step direct application of the self adhesive flowable composite resin (Vertise Flow) can be used without the incorporation of the additional primer (Embrace First Coat) step as they showed comparable results. Diamond stone roughening can be a good alternative to hydrofluoric acid. Clinical recommendations: The one step direct application of the self adhesive flowable composite resin (Vertise Flow) can be used effectively without the incorporation of the additional primer (Embrace First coat) step. When attempting to use the two steps system of First Coat plus Vertise Flow, it should not be used with hydrofluoric acid etching.
\end{abstract}

\section{INTRODUCTION}

Chipping or fracture of veneering porcelain is a common problem that may occur in all types of ceramic restoration. Despite that much more efforts are subjected to improve the bonding between the ceramic and the underlying metal framework in porcelain fused to metal restorations (PFM), fractures of ceramic may still occur under some clinical conditions. In addition to the costly and functional problems it poses for both the patient and the dentist, it may also present an esthetic problem that need to be treated as soon as possible. Therefore,

\footnotetext{
* Fixed Prosthodontics Department, Faculty of Dental Medicine, Boys, Cairo, Al-Azhar University.

** Associate Professor, Fixed Prosthodontics Department, Faculty of Dental Medicine, Boys, Cairo, Al-Azhar University.

*** Associate Professor, Fixed Prosthodontics Department, Faculty of Dental Medicine, Boys, Cairo, Al-Azhar University.

**** Professor, Fixed Prosthodontics Department, Faculty of Oral And Dental Medicine, Misr International University, Faculty of Dental Medicine, Boys, Cairo, Al-Azhar University, Egypt.
} 
using a chair side intra-oral repair option may be a simple alternative method to the total replacement of the restoration and may provide a clinicallyacceptable and reliable immediate solution.

It is a multi-factorial problem that could be related to various causes. Over many years, numerous studies have focused on the reasons of metal ceramic restoration failure. One of the main causes of failure may be due to the differences of modulus between ceramic materials and metal. In feldspathic porcelain, the leucite crystals imbedded in the glass matrix contract more than the surrounding glass matrix during cooling of the ceramics. This will lead to the development of compressive tangential stresses around the leucite particles in addition to the cracks around and within the crystals ${ }^{(1-3)}$.

Other studies have reported that failure of metal ceramic restorations is mainly attributed to the environmental factors especially moisture. A study about metal ceramic restorations in moist environment found that, metal ceramic restorations are decreased in their strength by 20 to $30 \%$. Another study reported that moisture is able to hydrolyze the silicate bonds in the glassy matrix of ceramics in the presence of mechanical stresses. The porcelain restoration usually functions in moisture which will allow static fatigue to start the propagation of fractures along the microcracks resulting in failure of the restoration ${ }^{(4,5)}$.

The moisture environment in the oral cavity was found to aggravate the strength of dental ceramics. In the presence of moisture, the silicon oxygen bond between the ceramics and the metal becomes weaker (6). The effect of fatigue and water in the oral cavity are considered the most important factors in the durability of porcelain fused to metal restorations, but the effect of other environmental factors such as saliva and different types of drinks is still unknown.

The most important reason for ceramic failure is crack propagation within the ceramic. In nearly all ceramic surfaces, minute scratches are present and act as sharp notches whose tips are very narrow as the spaces between atoms within the material. Therefore, stress concentration at the tips of those scratches causes the stress to reach the theoretical stress of the porcelain at a relatively lower value leading to breakdown of the bond at the notch tip and crack propagation ${ }^{(7)}$.

Long span bridges with underlying metal substructure that flexes under heavy or complex loading causes porcelain fracture ${ }^{(8)}$. It was also reported that other reasons for fracture of ceramic restoration may be due to technical mistakes during laboratory fabrication of the restoration such as improper sandblasting of the metal substrate before building up the porcelain or the occasional presence of pores inside the ceramics ${ }^{(9)}$. The same results were also confirmed that those laboratory mistakes will increase the failure of PFM restorations ${ }^{(10)}$.

Other studies demonstrated the importance of microcracks present in the ceramic restorations.

Microcracks could be caused by melting, condensation, and sintering process of ceramics on the metal framework due to the thermal coefficient differences ${ }^{(11)}$. Other factors such as faulty metal framework design, incompatible coefficient of thermal expansion between the metal and ceramics, excessive ceramic thickness with inadequate metal support, technical flaws in the porcelain application and occlusal forces or trauma ${ }^{(12)}$.

On the other hand, mechanical fatigue is governed by multiple factors which are related to the material properties including microstructure, fracture toughness, crack length and applied stresses (13). Another study reported that all the efforts should be made to minimize the air entrapment between ceramic particles to prevent porosity from impairing esthetics as well as promoting fracture ${ }^{(14)}$. In a finite element analysis, it was reported that the presence of void in the ceramics have a significant effect on the fracture resistance ${ }^{(15)}$. Another reason for ceramic fracture was related to inadequate tooth 
preparation, which will eventually result in too little interocclusal space for metal substructure and the veneering ceramics. It was concluded that improper design of the restoration for the occlusion is the major cause of failure ${ }^{(16)}$.

\section{Methodology:}

A total of 40 circular porcelain fused to metal specimens with $1 \mathrm{~cm}$ in diameter and $4 \mathrm{~mm}$ thickness was fabricated using feldspathic porcelain (VITA VMK Master, VITA, Germany) and nickel chromium base metal alloy (Wiron Light, BEGO, Germany). All 40 samples were subjected to 3000 cycles of thermo-cycling before the repair was performed. The specimens were divided into two equal groups of 20 samples each according to the repairing system used. (V; one step self- adhesive flowable composite resin, Vertise Flow, Kerr) and (F; two steps, Embrace First Coat, Pulpdent) followed by the application of self-adhesive composite resin (Vertise Flow). Each group of the two main groups was divided into two equal subgroups of 10 samples each according to the surface treatment applied before repair. (D; diamond stone surface roughening) and ( $\mathrm{H}$; hydrofluoric acid etching). Half of the specimens were subjected to accelerated photo-thermal aging before testing the shear bond strength.

A custom made stainless steel mould was fabricated to produce 40 wax patterns. The mould was circular in shape with $1.0 \mathrm{~cm}$ diameter and varying internal depths. Half of the mould is $0.2 \mathrm{~cm}$ in depth, and the other half is $0.4 \mathrm{~cm}$ in depth (Figure 1). The patterns were sprayed with a surface tension reducing agent then invested in gypsum free phosphate bonded investment material and the metal discs were obtained by lost wax technique.

The samples were treated according to the manufacturer's recommendation for building up of the conventional feldspathic porcelain. The discs were sandblasted with aluminum oxide particle $50 \mu \mathrm{m}$ in size with a 3-4 bar pressure on both halves

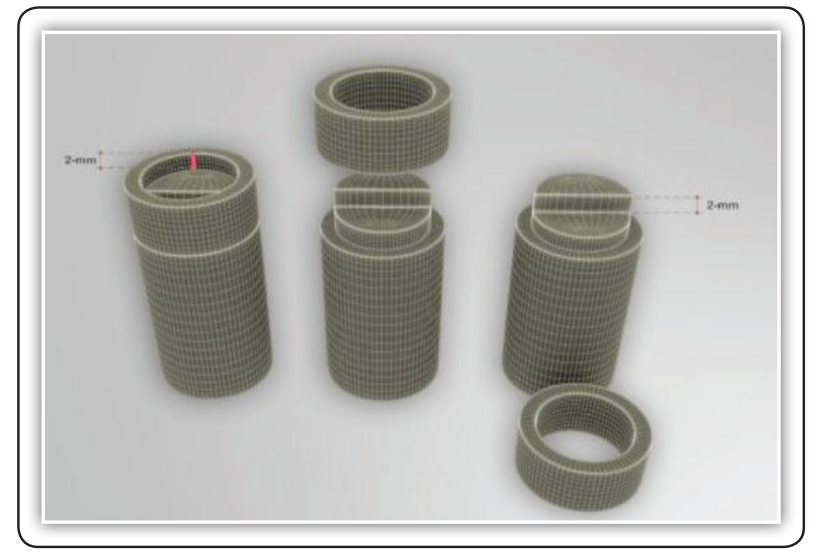

FIG (1) Diagram showing the custom made mould.

of the discs (Figure 2). The discs were cleaned by water and washed thoroughly. The porcelain was added to the thinner half of the samples while the samples are placed in a specially made stainless steel holder that is encircling the disk and allowing the porcelain to be added and condensed accurately while preserving the circumference of the sample and insuring that the added porcelain is $2 \mathrm{~mm}$ in thickness in all the tested specimens (Figure 3).

All 40 samples were subjected to thermo-cycling before the repair was performed. In this study, the number of cycles used was 3000 cycles. Dwell times were $25 \mathrm{~s}$. in each water bath with a lag time $10 \mathrm{~s}$. The low-temperature point was $5^{\circ} \mathrm{C}$. The hightemperature point was $55^{\circ} \mathrm{C}$.

In groups $\mathrm{VD}$ and $\mathrm{FD}$, the surfaces of the porcelain and the metal to be repaired were roughened with a diamond stone (TR.11) accompanied with a water coolant to avoid crack formation within the porcelain. For $\mathrm{VH}$ and $\mathrm{FH}$ groups; where the surfaces of the porcelain and metal to be repaired are subjected to acid etching by hydrofluoric acid; the acid gel was applied for one minute as recommended by the manufacturer and the surface was rinsed with a copious amount of water and dried with clean uncontaminated air.

Each of the repair materials to be tested was applied to the junction between porcelain and 
metal surfaces using a custom made stainless steel ring that allows the repair resin to be placed in a circular pattern with $5 \mathrm{~mm}$ diameter and $2 \mathrm{~mm}$ height exactly on the center of the disc (Figure 4). Half of the repairing resin is placed on the porcelain with a hemi-circular pattern of $2.5 \mathrm{~mm}$ radius, and the other $2.5 \mathrm{~mm}$ hemi-circular pattern is placed on metal.

For the groups repaired with the one step self adhesive flowable composite (Vertise Flow) only (V groups), the material was directly applied in layers as instructed by the manufacturer. After treating the surface with diamond stone or acid etching, the surface was rinsed for 10 seconds and dried for 5 seconds. Vertise Flow was dispensed onto

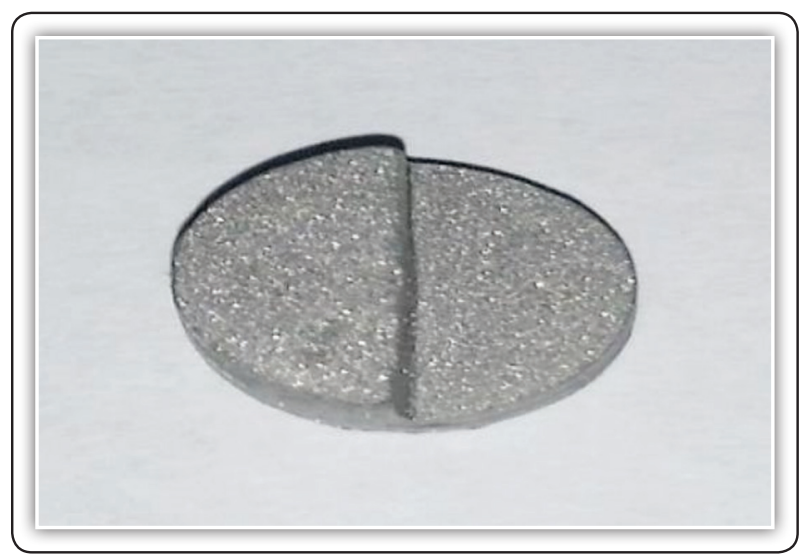

FIG (2) Sandblasted specimen.

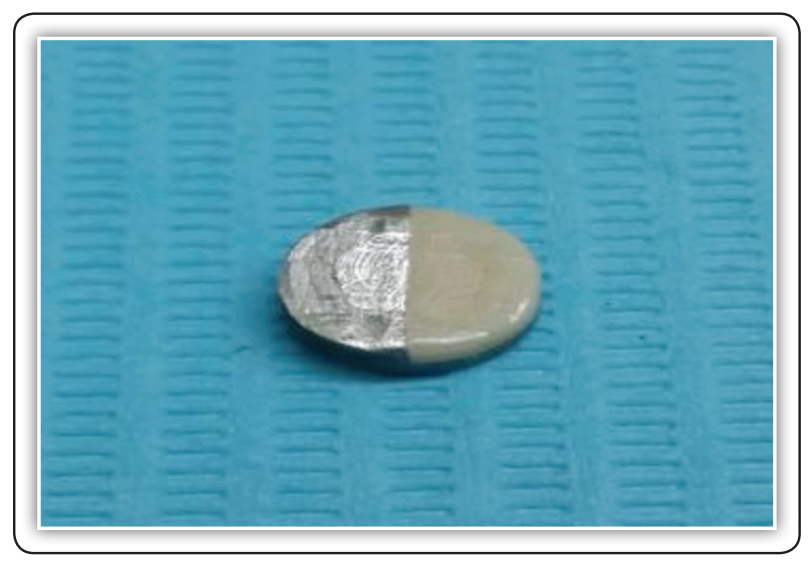

FIG (4) PFM specimen. the preparation and brushed to the bonding surface with moderate pressure for 15-20 seconds and light cured for 20 seconds to obtain a first thin layer $(<0.5 \mathrm{~mm})$ of resin. The material was then applied in increments over the first layer in a custom made mould till it reaches the thickness of $2 \mathrm{~mm}$ (Figure 5). Each increment was light cured for 20 seconds. For $\mathrm{F}$ groups, After roughening of the surfaces with $\mathrm{HF}$ acid or diamond stone, a thin layer of Embrace First-Coat is applied over the rinsed and dried surfaces with a flocked applicator tip. The First Coat layer was light cured using a LED curing light* for 20 seconds. The Vertise Flow composite resin was then applied following the same manufacturer's instructions mentioned before.

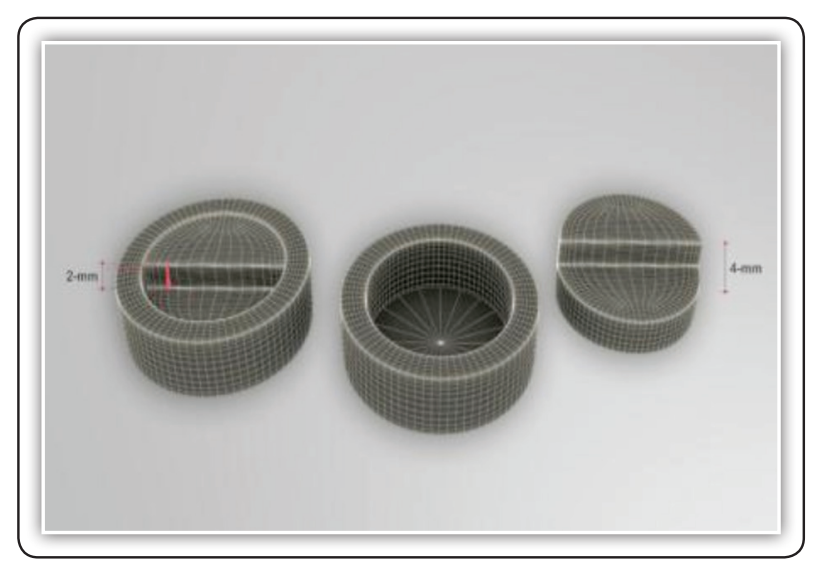

FIG (3) Diagram of the mould for porcelain build up

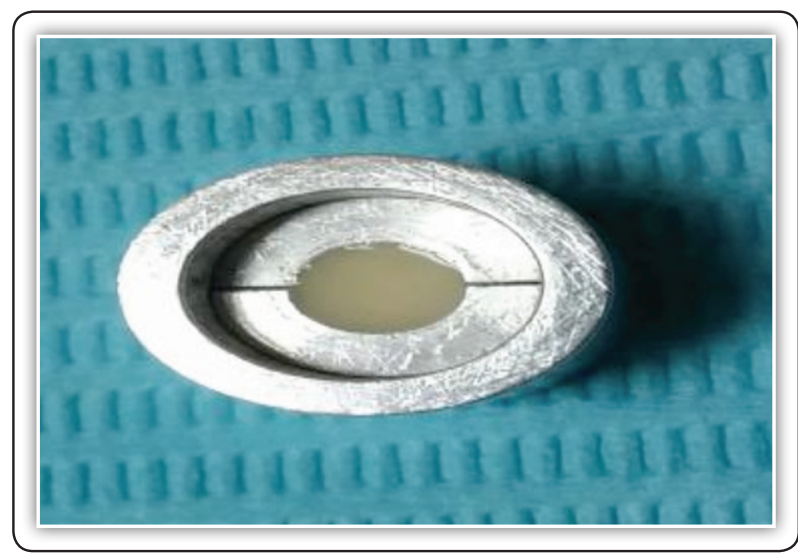

FIG (5) Mould for composite application. 
20 discs of the four different subgroups (VDA, VHA, FDA, FHA) were mounted on a stainless-steel plate with the repaired surfaces exposed to QUV accelerated aging chamber exposing them to UV light action, heat and humidity. The test conditions were alternating cycles of light and humidity at relatively elevated temperature. A cycle of 4 hours under UV light at $50{ }^{\circ} \mathrm{C}$ followed by a 4 hours cycle of condensing humidity at $50{ }^{\circ} \mathrm{C}$ until a total of 300 hours was achieved.
Shear bond strength was determined using NEXYGEN from Lloyd Instruments at a crosshead speed of $0.5 \mathrm{~mm} / \mathrm{min}$. Statistical analysis was carried out using Kolmogorov-Smirnov and Shapiro- Wilk tests.

\section{RESULTS}

The descriptive analysis revealed a variability in the shear bond strength values (MPa) (Table 1).

TABLE (1) Descriptive statistics of shear bond strength values (MPa)

\begin{tabular}{|c|c|c|c|c|c|c|c|c|c|}
\hline \multirow[b]{2}{*}{ Repair system } & \multirow{2}{*}{$\begin{array}{l}\text { Surface } \\
\text { treatment }\end{array}$} & \multirow[b]{2}{*}{ Aging } & \multirow[b]{2}{*}{ Mean } & \multirow[b]{2}{*}{ SD } & \multirow[b]{2}{*}{ Median } & \multirow[b]{2}{*}{ Minimum } & \multirow[b]{2}{*}{ Maximum } & \multicolumn{2}{|c|}{$95 \% \mathrm{CI}$} \\
\hline & & & & & & & & $\begin{array}{l}\text { Lower } \\
\text { bound }\end{array}$ & $\begin{array}{l}\text { Upper } \\
\text { bound }\end{array}$ \\
\hline \multirow{4}{*}{$\begin{array}{l}\text { Vertise } \\
\text { Flow }\end{array}$} & \multirow{2}{*}{$\begin{array}{c}\text { Diamond } \\
\text { Stone }\end{array}$} & Normal & 6.3 & 2.4 & 5.1 & 4.2 & 9.9 & 3.4 & 9.3 \\
\hline & & Aged & 4.9 & 1.4 & 4.9 & 2.7 & 6.7 & 3.1 & 6.7 \\
\hline & \multirow{2}{*}{ HF Acid } & Normal & 7.1 & 2.0 & 7.1 & 4.6 & 10.1 & 4.7 & 9.6 \\
\hline & & Aged & 5.3 & 1.4 & 4.5 & 4.3 & 7.5 & 3.6 & 7.1 \\
\hline \multirow{4}{*}{$\begin{array}{l}\text { Vertise Flow + } \\
\text { First Coat }\end{array}$} & \multirow{2}{*}{$\begin{array}{c}\text { Diamond } \\
\text { Stone }\end{array}$} & Normal & 5.5 & 1.1 & 5.1 & 4.2 & 6.8 & 4.1 & 6.9 \\
\hline & & Aged & 3.1 & 2.9 & 1.6 & 0.7 & 7.3 & 0.5 & 6.7 \\
\hline & \multirow{2}{*}{ HF Acid } & Normal & 8.4 & 3.3 & 7.5 & 4.9 & 13.6 & 4.3 & 12.5 \\
\hline & & Aged & 4.8 & 1.8 & 4.7 & 2.9 & 6.7 & 2.6 & 7.0 \\
\hline
\end{tabular}

\section{Effect of repair system}

When comparing the two repairing systems together, whether the surface of the samples was pretreated with diamond stone or acid etching in normal and aged specimens; there was no statistically significant difference between shear bond strength values of the two repair systems.

\section{Effect of surface treatment}

When comparing surface treatment by diamond stone roughening to hydrofluoric acid etching with each repairing system in normal and aged specimens; there was no statistically significant difference between shear bond strength values of the two surface treatments.

\section{Effect of aging}

When comparing the samples repaired with Vertsie Flow whether treated with diamond stone or acid etching; there was no statistically significant difference between mean shear bond strength values of normal and aged specimens. Similarly using Vertise Flow + First Coat repair system with samples treated by diamond stone; there was no statistically significant difference between mean shear bond strength values of normal and aged specimens. While using Vertise Flow + First Coat repair system with samples treated by hydrofluoric acid etching; normal specimens showed statistically significantly higher mean shear bond strength than aged specimens. 


\section{DISCUSSION}

Replacement of a failed restoration is not necessarily the most practical solution because of the obviously substantial costs and the complex nature of the restoration ${ }^{(17)}$. Besides some economic and technical reasons, it was reported that the cracks or crazing in the fractured area might become a haven for micro-organisms and plaque accompanied by staining ${ }^{(18)}$. On the basis of previous studies, a consensus was reached that the repeated firing cycles cause distortion of the ceramic restorations. Deformation or most of the distortion was found to occur especially during the initial oxidation of the alloys but small changes from 30 to $99.6 \mu \mathrm{m}$ were also examined at the margins of the restoration during the subsequent heating and ceramic applications ${ }^{(19,20)}$.

All 40 samples were subjected to thermo-cycling before the repair was performed to simulate the effect of oral environment on the porcelain and metal surfaces. Laboratory simulations of clinical service are often performed because clinical trials are costly and time consuming. Long-term water storage and thermo-cycling are accepted methods for the simulation of such aging and stressing conditions. Even though direct clinical correlations and conclusions cannot be drawn from these aging methods, their significant effects on the bonding interface have been demonstrated in different studies ${ }^{(21,22)}$.

It is well documented that roughening of the fractured surface of the metal-ceramic restoration is one of the important factors that contribute to an effective and durable bonding between resin composite and silica-based ceramics. ${ }^{(23-26)}$ This is because the increased roughness of ceramic surface improves the mechanical interaction of the resin cement to the ceramic surfaces and also increases the total surface energy of the ceramic surface, thus, its wettability ${ }^{(27,28)}$. Similarly, the roughening of metal alloy surface can also contribute to the bond strength of composites to metal substrate. Several studies found that roughening of a metal alloy surface resulted in a significant increase in bond strength of composite-to base metal alloy ${ }^{(27,29)}$.

Vertise Flow is a new self-adhering flowable composite resin that has some differences in its inorganic composition. According to its Technical Bulletin, Vertise Flow contains $1 \mu \mathrm{m}$ barium glass filler, prepolymerized filler, nano-sized colloidal silica and nanosized ytterbium fluoride. These inorganic fillers represent $70 \mathrm{wt} . \%$ of its total weight ${ }^{(30,31)}$. In their study, Czasch and Ilie ${ }^{(30)}$ compared the mechanical properties of self-adhering composite resin with those of four novel flowable composites and reported that self-adhering flowable composite resin presented best micromechanical properties among the tested flowable composites. Also, it has been reported that Vertise Flow self- adhering flowable composite resin exhibited the highest modulus and hardness among the tested flowable composite resins which present similar stiffness to that of non-flowable composite resin tested ${ }^{(31)}$. With regarding to these favorable mechanical properties, the use of this self-adhering flowable composite resin as a repair system was selected in this study.

The functional monomer of the self-adhering, flowable composite material used is glycerol phosphate dimethacrylate (GPDM), which is also used in the three-step total-etch adhesive OptiBond FL (Kerr Corp.), which has been reported in both laboratory and clinical research to be a wellperforming adhesive among the currently using adhesive systems ${ }^{(32,33)}$. The acidic phosphate group of the material is capable of etching and providing chemical adhesion to the calcium ions of tooth tissue, as well as to a variety of surfaces including silica-based ceramics ${ }^{(34)}$.

The adhesive primer (Embrace First-Coat) is a single component, unfilled resin that contains no solvent and is designed to penetrate and bond chemically and mechanically to etched or abraded 
surfaces. It is light cured and compatible with all composites. First-Coat eliminates the use of metal primers, silanes and bonding agents on ceramic and metal surfaces. The First Coat is a unique primer that acts as silane coupling agents enhancing the bond of any composite resin to any restoration, metal or porcelain surfaces ${ }^{(35,36)}$.

The hypothesis of this study was partially accepted. In comparing the shear bond strength values between the two systems used in this study in the subgroups that were not subjected to accelerated photo thermal aging, no significant difference was found between the two repairing systems regardless the surfaces were treated with diamond stone or hydrofluoric acid.

When evaluating the effect of the two surface treatments used in this study, no significant differences were found between subgroups either before or after accelerated photo thermal aging. These results are in disagreement with the results of the previous studies reported that acid etching with $9.5 \%$ hydrofluoric acid provided significantly higher bonds in comparison with the other treatment methods and concentrations. (37-41) Other studies in contrast agree with our study and consider hydrofluoric acid etching inadequate from the clinical point of view as it did not show significantly higher shear bond strength to metal or ceramics ${ }^{(42,}$ 43). However, due to the hazardous effect of this acid gel for both patient and operator ${ }^{(4,44)}$, it must be used very carefully during the repair of ceramic surfaces.

In addition, to evaluate the effect of the oral environment on both the surface treatment method and the repairing system used, half of the specimens were subjected to accelerated photo-thermal aging after the repair procedure was performed. The use of accelerated photo-thermal aging process has increased in dental researches recently ${ }^{(45,46)}$. This process simulates the effects of long-term exposure to environmental conditions through an accelerated weathering process that involves ultraviolet light exposure, temperature and humidity changes. ${ }^{(47)}$ Besides, previous studies have shown the effect of accelerated aging on the physical and mechanical properties of the liner materials ${ }^{(48,49)}$. The manufacturer of the weathering machine estimates that 300 hours of aging is equivalent to 1 year of clinical service intra-orally ${ }^{(45,50)}$. When the specimens were subjected to artificial photothermal aging, the differences between the two repairing systems were considered statistically insignificant, either when tested following acid etching or roughening with diamond stone.

The only significant difference after accelerated photo thermal aging was recorded between the two subgroups where the two steps system was used on etched surfaces before and after photo thermal aging. It was assumed that the lower bond strength of the two steps system after accelerated photo thermal aging when the surface was pretreated with hydrofluoric acid is related to the primer adhesive layer (Embrace First Coat), because hydrolytic instability of the primer adhesive results in degradation and water sorption ${ }^{(51,52)}$. Therefore, mechanical bonding is more effective than the use of only chemical bonding ${ }^{(53,54)}$. This in turn favors the resistance of the intimate contact between the self adhesive flowable composite (Vertise Flow) and the repaired metal- ceramic surface to accelerated photo thermal aging when the surface is pretreated with HF acid.

SEM evaluation were performed to the specimens subjected to accelerated photo thermal aging to compare the mode of failure between the two repairing systems and to evaluate the effect of the two surface treatment methods used on the metal-ceramic surface. The mode of failure was revealed predominantly adhesive in all specimens. The SEM evaluation for the surface roughness of the two surface treatment methods used is in accordance with the previous studies showed that hydrofluoric acid produced the most distinct pore and groove formation on the ceramic surfaces when 


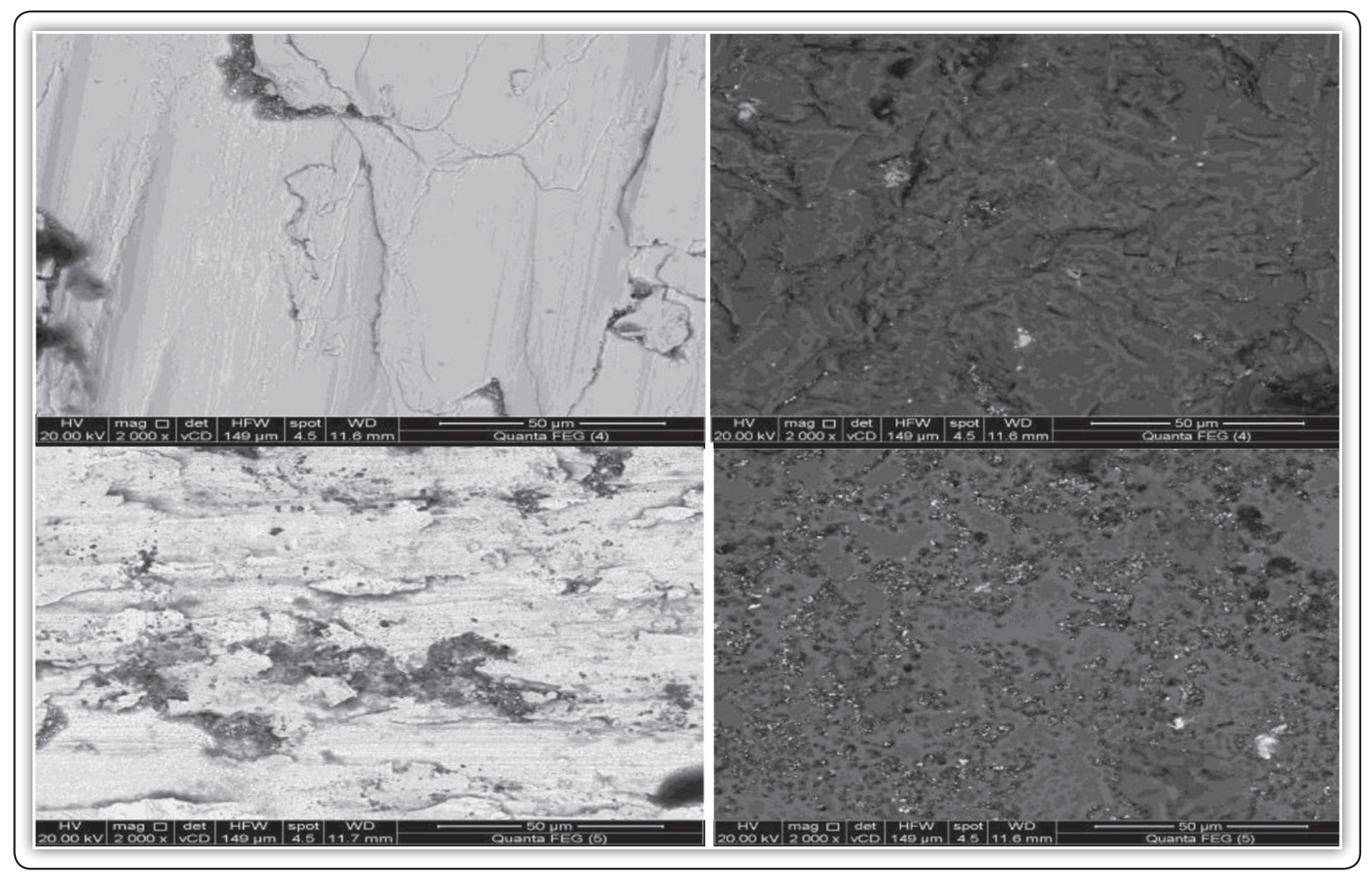

FIG (6) SEM images of the metal and feldspathic veneering ceramic after accelerated photo-thermal aging. (A) Metal pretreated with diamond stone (x2000); (B) Porcelain pretreated with HF (x2000); (C) Metal pretreated with diamond stone (x2000); (D) Porcelain pretreated with HF (x2000).

compared to diamond stone roughening ${ }^{(14,44,55,56)}$. These specimens exhibited considerably more irregularities, with deeper valleys and higher peaks. In the SEM analysis of these subgroups, a microporous structure with numerous microporosities and grooves on the surface can be seen.

However, the more distinct pores and grooves produced by hydrofluoric acid etching did not help in promoting the stability of the bond strength against accelerated photo thermal aging when compared to the less micro-porosities produced by diamond stone roughening. Therefore, we can assume that high roughness values for ceramic surfaces do not always mean that good bond strength will be obtained, and the geometric characteristics of the surface rather than the surface roughness should be one of the most important factors ${ }^{(57)}$.

\section{CONCLUSION}

Within the limitations of the current study the following conclusions were drawn:

1. The one step direct application of the selfadhesive flowable composite resin (Vertise Flow) can be used without the incorporation of the additional primer (Embrace First Coat) step as they showed comparable results.

2. Diamond stone roughening can be a good alternative to hydrofluoric acid because of the hazardous effect and the manipulation procedures of $\mathrm{HF}$ acid etching inside the oral cavity.

3. The decrease in bond strength after accelerated photo-thermal aging was noted in all subgroups, 
but it was significant only between the two subgroups where the two steps system was used on HF acid etched surfaces before and after photo thermal aging.

\section{Clinical recommendations:}

Within the limitations of this study, the following recommendations can be made:

1. The one step direct application of the selfadhesive flowable composite resin (Vertise Flow) can be used effectively without the incorporation of the additional primer (Embrace First coat) step.

2. When attempting to use the two steps system of the primer (Embrace First Coat) plus the selfadhesive flowable composite (Vertise Flow), it should not be used with hydrofluoric acid etching and its application should be restricted to diamond stone surface roughening.

\section{REFERENCES}

1. Hasselman D.P.H, Fulathy R.M. Proposed fracture theory of a dispersion-strengthened glass matrix. J Am Ceramic Soc. 1966; 49, 68.

2. Anusavice K.J, Zhang N.Z. Chemical durability of dicor and fluorocanasite-based glass-ceramics. J Dent Res. 1998; 77, 1553.

3. Denry I.L, Hollowey J.A, Rosentiel S.F. Effect of ion exchange on the microstructure, strength and thermal expansion behavior of a leucite-reinforced porcelain. J Dent Rese 1998; 77, 583

4. Sherill C.A, O'brein W.J. Transverse strength of aluminous and feldspathic porcelain. J Dent Res 1974; 53, 683.

5. Michalske T.A, Freiman S.W. A molecular interpretation of stress corrosion in silica. Nature 1982; 295, 511.

6. Dauskardt R.H, Marshall D.B, Ritchie R.O. Cyclic fatigue-crack propagation in magnesia-partially- stabilized zirconia ceramics. J Am Ceramic Soc 1990; 73, 893.

7. Lamon J, Evans A.G. Statistical analysis of bending strength for brittle solids: a multiaxial fracture a problem. J Am Ceramic Soc 1983; 66, 177.

8. Reuter J.E, Brose M.O. Failures in full crown retained dental bridges. Br Dent J 1984; 157, 61.
9. Oram D.A, Cruickshank-Boyd E.H. Fracture of ceramic and metalloceramic cylinders. J Prosth 1984; 52, 221.

10. Øilo G. Flexural strength and internal defect of some dental porcelain. Acta Odont Scand 1988; 46, 313.

11. Yamamoto M. In: Metal Ceramics, Principles and Methods of Makoto Yamamoto. Quint Pub Co. 1989; 447.

12. Diaz-Arnold A.M, Scheneider R.L, Aquilino S.A. Bond strengths of intraoral porcelain repair materials. Prosthet Dent 1989; 61, 305 .

13. Ban S, Anusavice K.J. Influence of test method on failure stress of brittle dental materials. J Dent Res 1990; 69 , 1791.

14. Evans D, Barghi N, Malloy C, Windeler S. The influence of condensation method on porosity and shade of body porcelain. J Prosthet Dent 1990; 63, 380.

15. Abu-Hassan M.I, Abu-Hammad O.A, Harrison A. Strains and tensile stress distribution in loaded disc-shaped ceramic specimens: an FEA study. J Oral Rehabil. 1998; 25, 490.

16. Creugers N, Snoek P, KA Yser A.F. An experimental porcelain repair system evaluated under controlled clinical conditions. J Prosthet Dent 1992; 68, 724.

17. Fan PL. Porcelain repair materials. Council on dental materials, instrument and equipment prepared at the request of the council. J Am Dent Assoc 1991; 122:124.

18. Walton JN, Gardner FM, Agar JR. A survey of fixed partial denture failures: length of service and reasons for replacement. J Prosthet Dent 1986; 56: 416.

19. Van Rensburg F, Starting H. Evaluation of the marginal integrity of ceramometal restorations: Part II. J Prosthet Dent1984; 52: 210 .

20. Richter-Snapp K, Aquilino SA, Svare CW, Turner KA Change in marginal fit as related to margin design, alloy type, and porcelain proximity in porcelain-fused-to-metal restorations. J Prosth Dent 1988; 60: 435.

21. Blatz MB, Sadan A, Maltezos C, Blatz U, Mercante D, Burgess JO. In vitro durability of the resin bond to feldspathic ceramics. Am J Dent 2004; 17:169-72.

22. Leibrock A, Degenhart M, Behr M, Rosentritt M, Handel G. In vitro study of the effect of thermo- and load-cycling on the bond strength of porcelain repair systems. J Oral Rehabil. 1999 ;26:130-7.

23. Shahverdi S, Canay S, Sahin E, Bilge A. Effects of different surface treatment methods on the bond strength of composite resin to porcelain. J Oral Rehabil 1998; 25: 699. 
24. Stangel I, Nathanson D, HSU CS. Shear strength of the composite bond to etched porcelain. J Dent Res1987; 66: 1460 .

25. Kupiec K, Wuertz K, Barkameier, W Wilwerding T. Evaluation of porcelain surface treatment and agents for composite to porcelain repair. J Prosthet Dent,1996; 76:119124.

26. Magne P, Cascione D. Influence of post-etching cleaning and connecting porcelain on the microtensile bond strength of composite resin to feldspathic porcelain. J Prosthet Dent, 2006; 96: 354-36.

27. Chung KH, Hwang YC. Bonding strengths of porcelain repair systems with various surface treatments. J Prosthet Dent 1997; 78: 267.

28. Blatz M.B, Sadan A, Blatz U. The effect of silica coating on the resin bond to the intaglio surface of procera all ceram restorations.Quintessence Int, 2003; 34:542-7.

29. Suliman AH, Swift EJ Jr. Perdigao J. Effects of surface treatment and bonding agents on bond strength of composite to porcelain. J Prosthet Dent. 1993; 70:118-20.

30. Czasch P, Ilie N. In vitro comparison of mechanical properties and degree of cure of a self-adhesive and four novel flowable composites. J Adhes Dent. 2013; 15:229-236.

31. Wei YJ, Silikas N, Zhang ZT, Watts DC. Hygroscopic dimensional changes of self-adhering and new resin-matrix composites during water sorption/desorption cycles. Dent Mater. 2011; 27:259-266.

32. Poitevin A, De Munck J, Van Ende A, Suyama Y, Mine A, Peumans M, Van Meerbeek B. Bonding effectiveness of selfadhesive composites to dentin and enamel. Dent Mater. 2013; 29:221-230.

33. De Munck J, Mine A, Poitevin A, Van Ende A, Cardoso MV, Van Landuyt KL, Peumans M, Van Meerbeek B. Meta-analytical review of parameters involved in dentin bonding. J Dent Res. 2012; 91:351-357.

34. Ahmad I. Compobond: Evolution of a new restorative dental material. Cosmetic Dent Eng. 2011; 2:26-37.

35. Nicoleta Ilie, Bogna Stawarczyk. Efficiency of different repair kits on bonding to aged dental resin composite substrates. Int J Adhesion Adhesive 2015; 58: 7-12.

36. Yasser L. Abdelnaby. Effects of cyclic loading on the bond strength of metal orthodontic brackets bonded to a porcelain surface using different conditioning protocols. The Angle Orthodontist 2011; 81:1064-1069.
37. Calamia JR, Vaidyanathan J, Vaidyanathan TK, Hirsch SM. Effects of coupling agents on bond strength of etched porcelain. J Dental Res 1985; 64: 296.

38. Thurmond JW, Barkmeier W, Wilwerding TM. Effect of porcelain surface treatments on bond strengths of composite resin bonded to porcelain. J Prosthet Dent 1994; 72: 355-359.

39. Edelhoff D, Marx R. Adha“sion zwischen Vollkeramik und Befestigungskomposit nach unterschiedlicher Oberflä - chenvorbehandlung. Deutsche Zahnärztliche Zeitschrift. 1995; 50; 112.

40. Ozcan M, Vallittu P.K. Effect of surface conditioning methods on the bond strength of luting cement to ceramics. Dent Mater. 2003; 19:725-31.

41. Ho G.W, Matinlinna J.P. Insights on ceramics as dental materials. Part II: Chemical surface treatments. Silicon, 2011; 3:117-123.

42. Pameijer CH, Louw NP, Fischer D. Repairing fractured porcelain: how surface preparation affects shear force resistance? J Am Dent Assoc 1996; 127: 203.

43. Matsumara H, Kawahara M, Tanaka T, Atsuta M. A new porcelain repair system with silane coupler, ferric chloride, and adhesive opaque resin. J Dent Res 1989; 68: 813 .

44. Ahmad I. Salvaging fractured porcelain crowns with a direct composite repair technique. Pract Proced Aesthet Dent. 2002; 14(3):233-238.

45. Anil N, Hekimoglu C, Sahin S. Color stability of heatpolymerized and auto-polymerized soft denture liners. J Prosthet Dent. 1999; 81:481-484.

46. Jin C, Nikawa H, Makihira S, Hamada T, Furukawa M, Murata H. Changes in surface roughness and colour stability of soft denture lining materials caused by denture cleansers. J Oral Rehabil. 2003; 30:125-130.

47. Saygili G, Sahmali S, Demirel F. Color stability of porcelain repair materials with accelerated ageing. J Oral Rehabil. 2006; 33:387-392.

48. Anil N, Hekimoglu C, Sahin S. The effect of accelerated aging on color stability of denture liners. J Oral Sci. 1998; 3:105-108.

49. Shotwell JL, Razzoog ME, Koran A. Color stability of long-term soft denture liners. J Prosthet Dent. 1992; 68:836-838

50. Douglas RD. Color stability of new-generation indirect resins for prosthodontic application. J Prosthet Dent. 2000; 83:166-170. 
51. Costa TR, Ferreira SQ, Klein-Júnior CA, Loguercio AD, Reis A. Durability of surface treatments and intermediate agents used for repair of a polished composite. Oper Dent. 2010; 35:231-7.

52. El-Askary FS, El-Banna AH, van Noort R. Immediate vs delayed repair bond strength of a nanohybrid resin composite. J Adhes Dent. 2012; 14:265-74.

53. Yesilyurt C, Kusgoz A, Bayram M, Ulker M. Initial repair bond strength of a nano-filled hybrid resin: effect of surface treatments and bonding agents. J Esthet Restor Dent. 2009; 21:251-60.

54. Rathke A, Tymina Y, Haller B. Effect of different surface treatments on the composite-composite repair bond strength. Clin Oral Investig. 2009; 13:317-23.

55. Raposo LH, Neiva NA, DaSilva GR, Carlo HL, et al. Ceramic restoration repair: report of two cases. J Appl Oral Sci. 2009; 17:140-4.

56. Tylka DF, Stewart GP. Comparison of acidulated phosphate fluoride gel and hydrofluoric acid etchants for porcelain-composite repair. J Prosthet Dent. 1994; 72:121-127

57. Erdemir U, Sancakli HS, Sancakli E, Eren MM, Ozel S Yucel T, Yildiz E. Shear bond strength of a new self-adhering flowable composite resin for lithium disilicate- reinforced CAD/CAM ceramic material. J Adv Prosthodont. 2014; 6: 434-443. 
